\title{
Fatigue Resistant Carbon Coatings for Rolling/Sliding Contacts
}

\author{
Harpal Singh ${ }^{1,2,3}$, Giovanni Ramirez ${ }^{1}$, Osman Eryilmaz ${ }^{1}$, Aaron Greco' ${ }^{1}$, Gary Doll ${ }^{3}$, Ali \\ Erdemir $^{1^{*}}$ \\ ${ }^{1}$ Argonne National Laboratory, Energy Systems Division, Lemont, IL, USA 60439 \\ ${ }^{2}$ Department of Mechanical Engineering, University of Akron, Akron, OH, USA 44325 \\ ${ }^{3}$ Timken Engineered Surface Laboratories, University of Akron, Akron, OH, USA 44325 \\ *Corresponding author (erdemir@anl.gov)
}

\begin{abstract}
The growing demands for renewable energy production have recently resulted in a significant increase in wind plant installation. Field data from these plants show that wind turbines suffer from costly repair, maintenance and high failure rates. Often times the reliability issues are linked with tribological components used in wind turbine drivetrains. The primary failure modes in bearings and gears are associated with micropitting, wear, brinelling, scuffing, smearing and macropitting all of which occur at or near the surface. Accordingly, a variety of surface engineering approaches are currently being considered to alter the near surface properties of such bearings and gears to prevent these tribological failures. In the present work, we have evaluated the tribological performance of compliant highly hydrogenated diamond like carbon coating developed at Argonne National Laboratory, under mixed rolling/sliding contact conditions for wind turbine drivetrain components. The coating was deposited on AISI 52100 steel specimens using a magnetron sputter deposition system. The experiments were performed on a PCS MicroPitting-Rig (MPR) with four material pairs at $1.79 \mathrm{GPa}$ contact stress, $40 \%$ slide to roll ratio and in polyalphaolefin (PAO4) basestock oil (to ensure extreme boundary conditions). The post-test
\end{abstract}


analysis was performed using optical microscopy, surface profilometry, and Raman spectroscopy. The results obtained show a potential for these coatings in sliding/rolling contact applications as no failures were observed with coated specimens even after 100 million cycles compared to uncoated pair in which they failed after 32 million cycles, under the given test conditions.

Keywords

Fatigue, Micropitting, Coating, DLC

\subsection{Introduction}

Wind energy is a promising and fastest growing power generation source [1]. An increase in the number of utility scale wind plants have increased the focus on the high operation and maintenance costs of wind turbines as these ultimately impact the cost of wind energy $[2,3]$. The drive train and actuators of wind turbines are major sources of failures arising from the variability of wind, torque reversals, fluctuation in energy demands, misalignment, and harsh environment conditions [4]. Bearings and gears in wind turbine drive trains suffer from failure modes like micropitting, scuffing, spalling, and smearing [5, 6], although these elements were designed to meet twenty year service lives assuming that proper lubrication and maintenance practices, and especially no unusual loads were encountered. If a bearing has a low concentration of non-metallic inclusions in the steel, operates at the designed contact stress, and maintains an adequate lubricant film thickness in the contact, then end of service life will be due to subsurface originated spalling [7].

Another fatigue phenomenon known as surface originated fatigue, which is caused by surface or near surface stress risers such as non-metallic inclusions, plastically deformed material, martensite transformation products, or several other factors. A particular type of surface initiated 
fatigue is known as micropitting which is a common failure mode encountered by gears and bearings [8]. Specifically, many main shaft spherical roller bearings in wind turbines are life limited due to spalls arising from micropitting wear [9]. Micropitting is associated with the initiation and propagation of micro-cracks in the direction of traction forces. The progression of micro-pits alters the surface profile of a bearing raceway or gear tooth which generates regions of large stress concentrations. The increase in localized stresses leads to fatigue failure through the formation of macro-pits or spalls. Micropitting is affected by several factors such as lubricant type, contaminants, temperature, contact stresses, hardness, sliding speed, and surface roughness [10].

Studies were carried out over the last few decades to understand the mechanism of micropitting. According to Morales-Espejel and Brizmer, micropitting depends on the lubrication conditions and roughness of the contacting surfaces, the presence of slip (between 0.5 and $2 \%$ ), and the associated boundary friction shear stress are required for the generation of micropitting [11]. Oila and Bull suggested that contact stress has the greatest impact on micropitting initiation, while the progression of micropitting is affected mostly by speed and slide to roll ratio [10].

Lubrication conditions are best quantified by the parameter lambda $(\lambda)$, which is the ratio of the lubricant film thickness to the composite surface roughness. Operating temperature, viscosity, and operating speed all affect the lubricant film thickness and hence $\lambda$. Brechot et al reported that oils with antiwear and extreme pressure additives that are used to prevent scuffing and wear can promote micropitting [12]. Micropitting has proven to be difficult to eliminate through lubricant chemistry alone. 
A number of solutions have been suggested to mitigate micropitting. Super-finishing is a process used on gear teeth to increase load bearing area and reduce the severity of asperity interactions in boundary lubrication (i.e., $\lambda<1$ ) [13]. Apart from super-finishing, other surface engineering techniques are also employed to reduce asperity contact and provide barriers to wear [14]. Physical vapor deposition (PVD) coatings composed of nitrides, sulfides and carbides were examined for their ability to prevent micropitting $[15,16]$. PVD coatings can be very effective at reducing or eliminating many wear modes [17]. Among these coatings, diamond like carbon (DLC) coatings are now being used in numerous applications for wear resistant purposes due to their desirable tribological performance [18]. DLC has been modified over the years to possess ultra-low friction and high wear resistance. DLC coatings can be doped or alloyed to increase their functionality. The properties (hardness, toughness, thermal stability) of DLC coatings are further increased by using novel coating architectures that consist of nanocrystalline precipitates and nanosized multilayers [19]. Hydrogen-free DLC coatings deposited from solid carbon targets can be extremely hard, while hydrogenated DLCs are usually much softer.

In this research, coatings having indentation hardness values greater than $10 \mathrm{GPa}$ are referred to as hard coatings, while coatings with indentation hardness values less than $10 \mathrm{GPa}$ are referred to as soft coatings. Precursor hydrocarbon gases such as methane and acetylene are typically used in the deposition of DLC that contain large amounts of hydrogen. Hard DLC have been shown to be very successful at mitigating many wear issues encountered by bearings and gears operation in boundary lubrication, including micropitting $[20,21]$. Surface treatments such as black oxide and phosphate conversions are also applied to bearings and gears to address micropitting [20, 22, 23]. These conversions are thick, sacrificial layers that work to rapidly break-in the surfaces of the components, reducing asperity contact, and delaying the onset of micropitting. Most of the 
studies reported on exploring the use of DLC to mitigate micropitting prevention were carried out with hard DLC coatings. Few if any studies were performed using soft DLC coatings.

In this research, a soft highly hydrogenated DLC coating was sputter-deposited on rings and roller specimens, and the tribological performance of the coated specimens was evaluated in a micropitting rig. Four different material pairs were tested in a polyalphaolefin (PAO) base stock oil. The as-deposited and tested specimens were then examined using optical microscopy and Raman spectroscopy in an attempt to understand underlying mechanisms.

\subsection{Materials and Methods}

\subsubsection{Test Apparatus}

A PCS Instruments Micropitting Rig (MPR) was used for testing. The MPR is a computer controlled three rings on roller tribometer. A $12 \mathrm{~mm}$ diameter roller is mounted in the center and in contact with three rings of $54 \mathrm{~mm}$ diameter at an angle of $120^{\circ}$. Figure 1 a shows the MPR test chamber and the arrangement of rings and roller inside the test chamber is shown in Figure 1b. A thermocouple was installed to measure the contact temperature and an external cooler was connected to control the temperature of the oil inside the test chamber. A load was applied to the top ring $\left(0^{\circ}\right.$ position) by means of motorized ball screw, and vibration was measured with a piezoelectric accelerometer. The rig has a capability to control entrainment speed $(0-4 \mathrm{~m} / \mathrm{s})$, slide to roll ratio (0 to $200 \%)$, temperature (25 - $135 \mathrm{C}$ ), and load (0 to $1250 \mathrm{~N})$.

\subsubsection{Test Material}

The test material used in this study and their properties are given in Table 1 . The roller had a $10^{\circ}$ chamfer on each side of a $1 \mathrm{~mm}$ track width as shown in Figure 2a. Rollers and rings were made of AISI 52100 steel and heat-treated to hardness values of 57-60 HRC and 62-65 HRC, respectively. The average surface roughness measured on the ring was about $\mathrm{R}_{\mathrm{a}}=0.3 \mu \mathrm{m}$ and 
roughness of the rollers was about $\mathrm{R}_{\mathrm{a}}=0.2 \mu \mathrm{m}$. No change in the surface roughness was observed after coating deposition. Figure $2 \mathrm{~b}$ shows an optical image of the cylindrical roller and the track width prior to testing.

Table 2 presents the test parameters used for evaluating the tribological performance of different material combinations. An unadditized polyalphaolefin base stock oil (KV@ $100{ }^{\circ} \mathrm{C}=3.90 \mathrm{cst}$ and Viscosity Index - 122) was used as the lubricant, which was used to eliminate the contribution of additives on the performance of the coatings and also to ensure that a severe boundary regime was in place. Tests were performed at a $430 \mathrm{~N}$ load, $1.79 \mathrm{GPa}$ max. Hertzian contact pressure, $3 \mathrm{~ms}^{-1}$ speed, $40 \%$ slide-to-roll ratio (SRR) and at a constant operating temperature of $55^{\circ} \mathrm{C}$. The initial $\lambda$ values were estimated to be 0.36 which confirms boundary lubrication regime.

Rollers and rings were coated with the highly hydrogenated diamond-like carbon (H-DLC) coating. This coating is a variant of the Near Frictionless Carbon coating developed at Argonne National Laboratory [24]. Prior to coating, specimens were ultrasonically cleaned using a solvent and dried in hot air before mounting on fixtures inside the deposition chamber. A pulsed magnetron sputtering system was used for the deposition of the coatings using one carbon target. Prior to deposition of carbon film, a thin $(\sim 50 \mathrm{~nm}) \mathrm{Cr}$ adhesion layer was deposited on the surface. The carbon target power was in the range of 1000-2000W and pulsed DC bias of -35 to 50 volts was supplied at $250 \mathrm{KHz}$. Methane $\left(\mathrm{CH}_{4}\right)$ and Argon (Ar) gas mixtures were maintained at $12 \mathrm{sccm}$ and $70 \mathrm{sccm}$, respectively. The final carbon coating thickness was in the range of $\sim 1$ $\mu \mathrm{m}$. 
Rolling element bearings operating in wind turbine gearboxes employ coatings that are either applied only to rolling elements (hard DLC) or both rolling elements and raceways (i.e., black oxide) [23]. The material pairs tested in this study were designed to be consistent with the application of coatings on wind turbine bearing components. The performance of the H-DLC coatings was examined by testing four material pairs: uncoated roller on uncoated rings, H-DLC coated roller on uncoated rings, uncoated roller on H-DLC coated rings, and H-DLC coated roller on H-DLC coated rings. The uncoated on uncoated pairing was used as the baseline in comparison with the other materials pairs. A value of 1200 Peak/Peak acceleration (vibration) was used as the cut-off limit in the tests to determine the cycles to failure. The $1200 \mathrm{P} / \mathrm{P}$ acceleration was a vibration reading from the accelerometer that was placed close to the contact zone and provided a view toward the progression of surface damage. Tests were suspended if the vibration exceeded the cut-off limit or exceeded 100 million contact cycles.

\subsection{Characterization and Performance}

Specimens were characterized by white light interferometry, optical microscopy, and Raman spectroscopy, prior and subsequent to testing. A Bruker 3D optical profilometer was used to measure the surface roughness and surface topography of specimens. A Renishaw green light Raman spectrometer with a wavelength of $633 \mathrm{~nm}$ was used to probe the structural chemistry of the coated and uncoated specimens both prior to and after testing. Raman Instrument was calibrated using an internal silicon reference, and the spectra were recorded in the range of 100$4000 \mathrm{~cm}^{-1}$. Raman spectra shown in Figure 3 were obtained from an uncoated steel roller, and untested H-DLC-coated roller, and the PAO4 base oil. Both steel and the as-deposited H-DLC show a broad and featureless spectrum that is typical for the materials. The PAO4 base oil shows 
Page 8 of 17

a strong characteristic feature at $2800 \mathrm{~cm}^{-1}$ and few small peaks between $1000 \mathrm{~cm}^{-1}$ and $1500 \mathrm{~cm}^{-}$

1.

Mechanical properties of the coating were measured by nanoindentation using a Hysitron Triboindenter TI - 950 equipped with a Berkovich diamond probe and loads in the range of 0.5 $\mathrm{mN}$ to $12 \mathrm{mN}$. Figure 4 shows the nano-indentation measurements on the H-DLC coatings. Nanoindentation measurements revealed that the hardness and elastic modulus values of the coating are about $6 \pm 1 \mathrm{GPa}$ and $55 \pm 10 \mathrm{GPa}$, respectively.

Traction coefficients and P/P acceleration are plotted against contact cycles and are shown in Figure 5 for the four materials pairs. Also shown in the Figure 5 are images of the roller wear tracks from each test. Vertical lines in the plot indicate instances where tests were stopped, the roller surface was inspected, and then the test was restarted. Figure 5a shows the measurements obtained from the uncoated on uncoated pairing. Whereas the traction coefficient remained approximately constant at $\sim 0.05$ through the test, the $\mathrm{P} / \mathrm{P}$ acceleration trace indicates that surface damage initiated at the beginning of the test and gradually increased until about 28 million cycles. Thereafter, the $\mathrm{P} / \mathrm{P}$ acceleration rapidly increased and exceeded the cut off limit at about 31 million cycles. The image of the roller surface shows a large amount of damage. A close inspection of the image coupled with the P/P acceleration data suggests that micropits formed rapidly on the roller surface, grew in size, and coalesced to produce an almost continuously damaged surface within the wear track.

Figure $5 \mathrm{~b}$ shows the traction coefficient and $\mathrm{P} / \mathrm{P}$ acceleration as a function of number of contact cycles on the roller for the H-DLC-coated roller on uncoated rings pairing. This test achieved 100 million cycles without exceeding the $\mathrm{P} / \mathrm{P}$ acceleration limit. The traction coefficient 
remained steady at $\sim 0.05$ for first 40 million cycles and then began to decrease gradually until about 65 million cycles, and then remained steady for the rest of period at $\sim 0.035$. The P/P acceleration was inversely correlated with the traction coefficient. The optical image of the roller wear track after test termination is shown on right, and the image shows that small regions of the coating delaminated. Figure $5 \mathrm{~b}$ suggests that the vibration increase may be due to isolated regions of coating delamination on the roller, the reduction in traction coefficient correlated with the formation of tribofilm. Since the vibration and traction curves are inversely co-related, it is possible that the delaminated material is participating in the tribofilm formation.

Figure 5c shows the traction coefficient and $\mathrm{P} / \mathrm{P}$ acceleration as a function of number of contact cycles for the pairing of the uncoated roller and H-DLC-coated rings. No changes in the traction coefficient or $\mathrm{P} / \mathrm{P}$ acceleration were observed in the test. The traction coefficient was measured to be about $\sim 0.04$ and the $\mathrm{P} / \mathrm{P}$ acceleration value was $\sim 200$ after completing 100 million cycles. The image of the uncoated steel roller shown on the right does not show any significant damage and that a tribofilm was generated over a large region of the wear track.

Figure 5d shows the traction coefficient and P/P acceleration as a function of number of contact cycles for the pairing of the H-DLC-coated roller and H-DLC-coated rings. The test was suspended after 100 million cycles. The traction coefficient was constant at $\sim 0.04$ throughout the test while the P/P acceleration increased slightly after about 45 million cycles from a value of 200 to 300 and remained at this value until the end of test. The image of the wear track show mild surface damage on the roller surface (see Figure 6d). 
All the tests where at least one surface was coated with the H-DLC lasted for 100 million cycles without experiencing a significant amount of surface damage. Figures 6a-d show high magnification topographical images of roller surfaces after testing for (a) uncoated roller on uncoated rings (b) H-DLC-coated roller on uncoated rings (c) uncoated roller on H-DLC-coated rings, and (d) H-DLC-coated roller on H-DLC-coated rings.

Roller wear was quantified according to a change in width of the roller wear track. An optical microscope was used to measure the track width at multiple locations prior and subsequent to testing. Values shown in Figure 7 are averages and standard deviations of four measurements of the change in roller track width. The data shown in the Figure 7 is based on the difference in initial and final track width divided by the total number contact cycles after failure or after termination. The total change in width of wear track was below $50 \mu \mathrm{m}$ in all tests but the uncoated pairing showed the largest change in track width. A clear trend is seen between change in track width and the amount of coating available to participate in the tribological contact. For example, the least amount of coating passing through the contact was for the H-DLC-coated roller on uncoated ring pair, while the largest amount of coating passing through the contact was for the H-DLC-coated roller on H-DLC-coated ring pair, considering the difference in coated sample surface area. However, statistically no differences were observed between uncoated roller/coated rings and coated roller/coated ring pairs. This trend suggests that the wear occurring on the roller depended upon the amount of H-DLC present in the contacts.

Raman spectra obtained on the tested roller specimens are shown in Figure 8. No significant differences are observed from spectrum of the untested roller in Figure 3 and the spectrum of the steel roller after testing. The Raman spectrum from the H-DLC-coated roller on uncoated rings pairing shows D and G peaks at around $1332 \mathrm{~cm}^{-1}$ and $1580 \mathrm{~cm}^{-1}$, respectively, which are typical 
of DLCs with high $\mathrm{sp}^{2}$ bond characters [25]. A minor peak around $670 \mathrm{~cm}^{-1}$ corresponds to $\mathrm{Fe}_{3} \mathrm{O} 4$ [26] that was probably generated from asperities on the rings. The Raman spectrum of the tribofilm formed on the roller during the uncoated roller on H-DLC-coated ring test shows similar D \& G features, a strong peak at $670 \mathrm{~cm}^{-1}$ from $\mathrm{Fe}_{3} \mathrm{O}_{4}$ or $\mathrm{FeO}$, and minor peaks around $222 \mathrm{~cm}^{-1}$ and $298 \mathrm{~cm}^{-1}$ from $\alpha-\mathrm{Fe}_{2} \mathrm{O}_{3}$ [26]. Since the tribofilm formed on the roller in the uncoated roller on H-DLC coated ring test has similar D \& G features in its Raman spectrum as the Raman spectra of the wear tracks from the H-DLC-coated roller on H-DLC-coated ring and H-DLC-coated roller on uncoated ring testing, there is a strong indication that the H-DLC coating undergoes a transition from its initial amorphous hydrocarbon state to disordered graphite within the wear track and then transfers from the coated rings to the wear track on the uncoated roller. The difference on the left part of the spectra in H-DLC-coated roller on H-DLCcoated ring, could be due to the photoluminescence from the hydrogen.

\subsection{Discussion}

Experimental results showed that the uncoated, steel on steel, material pair failed after 32 million cycles due to excessive surface damage. Large pits were observed on the roller due to damage accumulation and caused the P/P acceleration to exceed the cut-off limit. Based upon the observations of Fajdiga et al., the surface damage on the roller appears to have initiated with micropits, evolved into macropits, that coalesced and formed the continuous surface damage in the wear track [27]. Remarkable reductions in surface damage of the roller were observed when one or both elements were coated with H-DLC. Traction coefficients were $\sim 0.04$ and remained relatively constant throughout the testing for the three cases where at least one of the contacting surfaces was coated. Furthermore, no failures were observed and the tests were suspended after 100 million cycles. H-DLC appears to be a promising surface treatment candidate to mitigate 
fatigue-initiated micropitting wear on surfaces of components operating in low $\lambda$ ratio rolling and rolling/sliding contacts.

Friction reduction and wear protection are the primary motivations for using coatings on bearings and gears. Surface modifications that use coatings and thin films offer numerous technical advantages over untreated materials. Under boundary conditions in wind turbine drive trains, PVD coatings such as WC/a-C:H, and conversion coatings such as black oxide are widely used on the bearings and gears to improve tribological performance. Although conversion coatings are typically considered to be sacrificial and used primarily to prevent adhesive wear damage during run-in, new evidence has been generated that suggests that black oxide surface treatments on the raceways and rollers of wind turbine gearbox bearings may delay the onset of another failure mode termed white etch cracking [28]. Mahmoudi et al. [20] and Evans et al. [23] reported that black oxide is not an attractive candidate for preventing scuffing wear arising from roller/raceway skidding in highly stressed, low $\lambda$ environments. Although a hard WC/a-C:H (14 GPa) coating applied to the rolling elements of bearings functioned very well in mitigating micropitting, scuffing, and fatigue life reduction from debris damage [29], fracture-type wear of the coating was observed to occur at high contact stress cycles and $\pm 10 \%$ slide/roll ratios [20]. Hard WC/aC:H coating is believed to provide wear protection by polishing the uncoated mating surface and forming a barrier to the adhesive interactions of asperities [29]. Therefore both black oxide and $\mathrm{WC} / \mathrm{aC}: \mathrm{H}$ display the ability to increase $\lambda$ and transition the lubrication regime from boundary to mixed. Fewer investigations have been performed on the abilities of soft coatings to improve fatigue performance. Moorthy et al compared the rolling contact fatigue performance of a soft $\mathrm{Nb}-\mathrm{S}$ coating to a hard $\mathrm{WC} / \mathrm{a}-\mathrm{C}: \mathrm{H}$ coating $[15,30]$. Although the $\mathrm{Nb}-\mathrm{S}$ coating exhibited no polishing effect during the tests, no significant micropitting was observed. Mutyala et al 
examined the performance of balls coated with a soft Ti-doped $\mathrm{MoS}_{2}$ and found a significant increase in the rolling contact fatigue life of M50 steel specimens over uncoated specimens [31, 32]. In that study, it was reported that $\mathrm{MoS}_{2}$ from the coating combined with hydrocarbons from the synthetic base oil to form a a-C:H/MoS 2 tribofilm on the uncoated M50 rods. It was speculated that this tribofilm was responsible for the significant increase in rolling contact fatigue life of the rod specimen. Clearly soft coatings like $\mathrm{Nb}-\mathrm{S}$, Ti-MoS 2 , and H-DLC must function differently from hard coatings like $\mathrm{WC} / \mathrm{a}-\mathrm{C}: \mathrm{H}$ to provide fatigue life improvements to steel components. Furthermore, since black oxide surface conversions do not mitigate micropitting (surface fatigue wear), the soft coatings must also function differently from a soft black oxide [20].

Based upon the observations gleaned from this study, and previously reported studies on rolling contact fatigue studies of soft coatings, it is speculated here that the H-DLC coating functions similarly to the Ti-MoS 2 coating in mitigating surface fatigue. That is, carbon from the H-DLC (and also possibly from the synthetic base oil) forms an amorphous carbon tribofilm containing iron oxide $\left(\mathrm{Fe}_{3} \mathrm{O}_{4}\right)$ on uncoated steel surfaces during testing. This notion is supported by the Raman spectrum of the tribofilm formed on the uncoated roller (H-DLC ring/uncoated roller pairing) shown in Figure 8. The spectrum also shows the D and G mode vibrational signature of amorphous carbon. The low friction of the amorphous carbon tribofilm may be sufficient to reduce the magnitude of shear stresses generated on the roller surface during testing. MoralesEspejel and Brizmer point out that the presence of slip and the associated boundary friction shear stress are required for the generation of micropitting [11]. Lubricant additives or low friction coatings that can reduce boundary friction shear stress should delay or mitigate micropitting. A friction coefficient between $0.001-0.005$ and wear rates between $10^{-11}-10^{-10} \mathrm{~mm}^{3} / \mathrm{Nm}$ have been 
measured on H-DLC films in vacuum environments [33]. The H-DLC coating has a low friction coefficient that may delay the onset of micropitting and increase fatigue life through a reduction in shear stresses. The compliant H-DLC resist fracture and delamination of the coating under high contact stress cycles and high slide/roll ratios.

\subsection{Conclusions}

This research evaluated the tribological performance of highly hydrogenated diamond like carbon films in mixed rolling and sliding contacts for bearings and gears in wind turbine drive train. H-DLC films were deposited on cylindrical specimens and compared against untreated samples using PAO4 synthetic base oil as a lubricant. H-DLC coated samples provided significant improvement in mitigating surface fatigue (micropitting) compared to uncoated steel samples under the current test conditions. The results concluded from the experimental investigation are as follows:

- Nano-indentation results revealed that the coatings are highly elastic in nature and have hardness values ( $6 \mathrm{GPa})$ comparable to that of steel substrate.

- Uncoated steel/steel pairs failed after 32 million cycles whereas no failure was observed with soft-highly hydrogenated diamond like carbon coated test samples up to 100 million cycles.

- Raman analysis showed microstructural transformations of the H-DLC inside the roller wear track.

- Results indicate that coating only one side of the material pair is sufficient to delay the onset of surface fatigue of test rollers by more than 100 million cycles. H-DLC appears to be an effective solution for components that suffer from surface initiated fatigue. 
- Further work is needed to evaluate the performance of H-DLC on actual bearings and gears in fully formulated lubricants.

\section{Acknowledgement:}

Funding provided by U.S. Dept. of Energy Office of Energy Efficiency and Renewable Energy (EERE), Vehicle Technology Office and Wind and Water Power Technology Office. The Raman spectroscopy was performed at the Center for Nanoscale Materials, a U.S. Department of Energy, Office of Science, Office of Basic Energy Sciences User Facility under Contract No. DE-AC02-06CH11357

\section{References:}

1. Sheng, S., Renewable, N., Veers, P.S., Renewable, N.: Wind Turbine Drivetrain Condition Monitoring - An Overview Wind Turbine Drivetrain Condition Monitoring An Overview. (2015).

2. Sheng, S.: Gearbox Reliability Database : Yesterday, Today, and Tomorrow. (2014).

3. Errichello, R., Sheng, S., Keller, J., Greco, A.: Wind Turbine Tribology Seminar. Presented at the (2011).

4. Musial, W., Butterfield, S., McNiff, B.: Improving Wind Turbine Gearbox Reliability Preprint. Eur. Wind Energy Conf. 1-13 (2007).

5. Doll, G.L.: Current Challenges in Wind Turbine Tribology. In: http://www.anl.gov/sites/anl.gov/files/Tribological Challenges in Wind Turbine Technology 2014_doll_1_1.pdf (2014).

6. Doll, G.L., Kotzalas, M.N., Kang, Y.S.: Life-limiting wear of wind turbine gearbox bearings: Origins and solutions. Eur. Wind Energy Conf. Exhib. 2010, EWEC 2010. 4, 2559-2568 (2010). 
7. Sadeghi, F., Jalalahmadi, B., Slack, T.S., Raje, N., Arakere, N.K.: A Review of Rolling Contact Fatigue. J. Tribol. 131, 041403 (2009).

8. Sheng, S.: Wind Turbine Micropitting Workshop : A Recap Wind Turbine Micropitting Workshop : A Recap. (2010).

9. Kotzalas, M.N., Doll, G.L.: Tribological advancements for reliable wind turbine performance. Philos. Trans. A. Math. Phys. Eng. Sci. 368, 4829-50 (2010).

10. Oila, A., Bull, S.J.: Assessment of the factors influencing micropitting in rolling/sliding contacts. Wear. 258, 1510-1524 (2005).

11. Morales-Espejel, G.E., Brizmer, V.: Micropitting Modelling in Rolling-Sliding Contacts: Application to Rolling Bearings. Tribol. Trans. 54, 625-643 (2011).

12. P. Brechot, A.B. Cardis, W.R. Murphy, J.T.: Micropitting resistant industrial gear oils with balanced performance. Ind. Lubr. Tribol. 52, 125-136 (2000).

13. Hashimoto, F., Melkote, S. N., Singh, R., \& Kalil, R.: Effect of finishing methods on surface characteristics and performance of precision components in rolling/sliding contact. Int. J. Mach. Mach. Mater. 6, 3-15.

14. Doll, G.L.: Adressing wind turbine tribological challenges with surface engineering. In: http://www.anl.gov/sites/anl.gov/files/Addressing\%20Wind\%20Turbine\%20Tribological \%20Challenges\%20with\%20Surface\%20Engineering_doll_1_3.pdf (2014).

15. Moorthy, V., Shaw, B. a.: Effect of as-ground surface and the BALINIT?? C and Nb-S coatings on contact fatigue damage in gears. Tribol. Int. 51, 61-70 (2012).

16. Joachim, F., Kurz, N., Glatthaar, B.: Influence of coatings and surface improvements on the lifetime of gears. VDI Berichte. 2, 565-582 (2002).

17. Doll, G.L., Ribaudo, C.R., Evans, R.D.: Engineered Surfaces for Steel Rolling Element Bearings and Gears. Mater. Sci. Technol. Forum -Association Iron Steel Technol. 367376 (2004).

18. Erdemir, A., Donnet, C.: Tribology of diamond-like carbon films: recent progress and future prospects. J. Phys. D. Appl. Phys. 39, R311-R327 (2006).

19. Donnet, C., \& Erdemir, A. ed: Tribology of diamond-like carbon films: Fundamentals and applications. Springer Science \& Business Media (2007).

20. Mahmoudi, B., Tury, B., Hager, C.H., Doll, G.L.: Effects of Black Oxide and a WC/a-C:H Coating on the Micropitting of SAE 52100 Bearing Steel. Tribol. Lett. 58(2), 1-9, (2015).

21. http://www.oerlikon.com/balzers/en/products-services/balinit-coatings/balinit-c-star/. 
22. Devlin, M.T., Turner, T.L., Thompson, K., Kolakowski, K., Garelick, K., Guevremont, J.M., Jao, T.: Effect of Phosphate Coatings on Fatigue and Wear. NLGI 74th Annu. Meet. (2007).

23. Evans, R.D., Hager, C.H., Kang, Y.S., Doll, G.L.: Comparison of Black Oxide and Tungsten Carbide-Reinforced Diamond-Like Carbon (WC/a-C:H) Surface Treatments for Rolling Element Bearings. Tribol. Trans. 58, 444-453 (2015).

24. Erdemir, A., Eryilmaz, O.L., Fenske, G.: Synthesis of diamondlike carbon films with superlow friction and wear properties. J. Vac. Sci. Technol. A Vacuum, Surfaces, Film. 18, 1987 (2000).

25. Ferrari, A. C., \& Robertson, J.: Interpretation of Raman spectra of disordered and amorphous carbon. Phys. Rev. B. 61, 14095 (2000).

26. Thibeau, Richard J., Chris W. Brown, and R.H.H.: Raman spectra of possible corrosion products of iron. Appl. Spectrosc. 32, 532-535 (1978).

27. Fajdiga, G., Sraml, M.: Fatigue crack initiation and propagation under cyclic contact loading. Eng. Fract. Mech. 76, 1320-1335 (2009).

28. Evans, M. H. "White structure flaking (WSF) in wind turbine gearbox bearings: effects of'butterflies' and white etching cracks (WECs)." Materials Science and Technology 28.1 (2012): 3-22.].

29. Eckels, M., M. N. Kotzalas, and G. L. Doll. "Attaining high levels of bearing performance with a nanocomposite diamond-like carbon coating." Tribology Transactions 56.3 (2013): 410-416]

30. Moorthy, V., Shaw, B. A.: An observation on the initiation of micro-pitting damage in asground and coated gears during contact fatigue. Wear. 297, 878-884 (2013).

31. Mutyala K. C., H Singh., R. D. Evans, G.L. Doll.: Deposition, Characterization, and Performance of Tribological Coatings on Spherical Rolling Elements. Surface and Coatings Technology. doi:10.1016/j.surfcoat.2015.06.075 (2015).

32. Mutyala K. C., H. Singh, R. D. Evans, G.L. Doll. Influence of $\mathrm{MoS}_{2}$ on the Rolling Contact Performance of Bearing Steel- A Different Approach. Tribology Letters. doi:10.1007/s11249-015-0638-7

33. Erdemir, A.: Genesis of superlow friction and wear in diamondlike carbon films. Tribol. Int. 37, 1005-1012 (2004). 


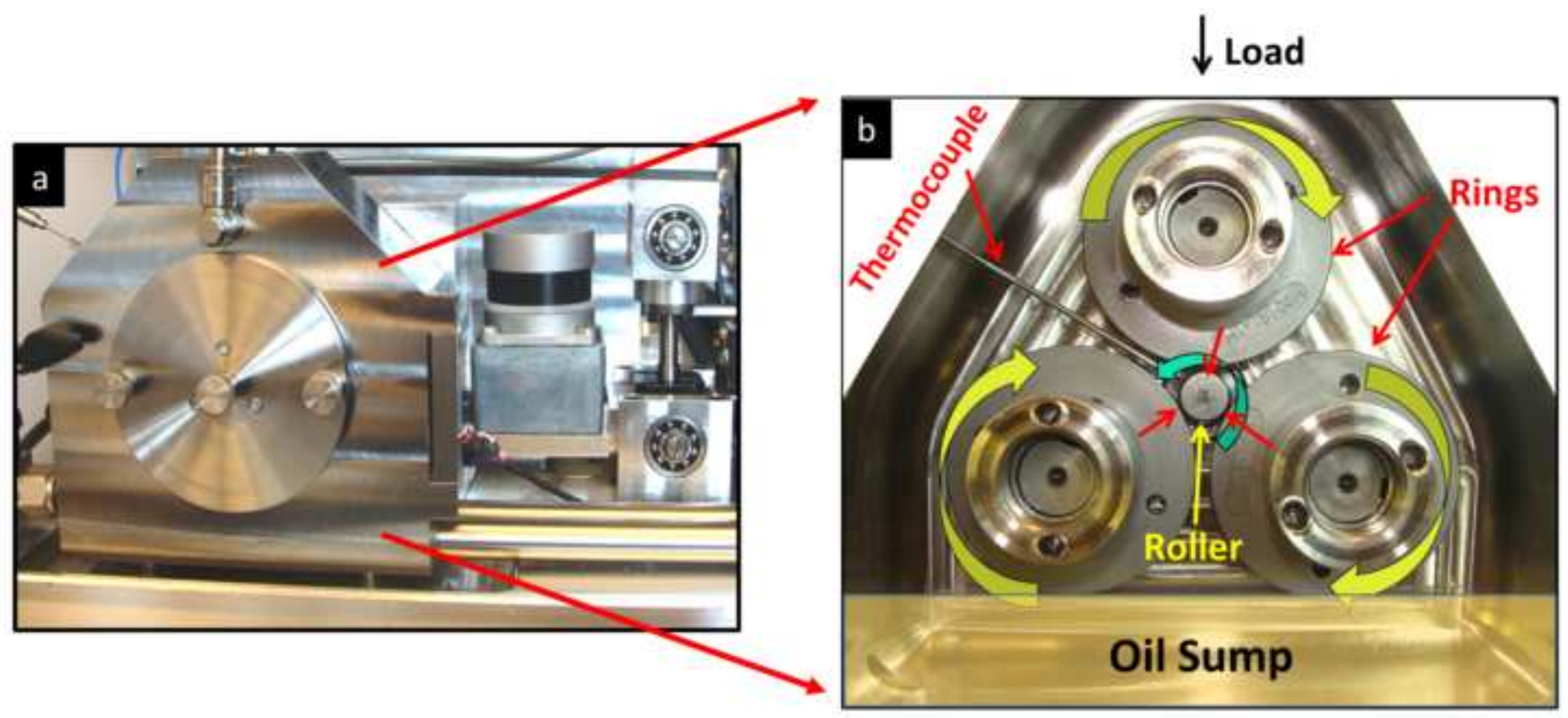



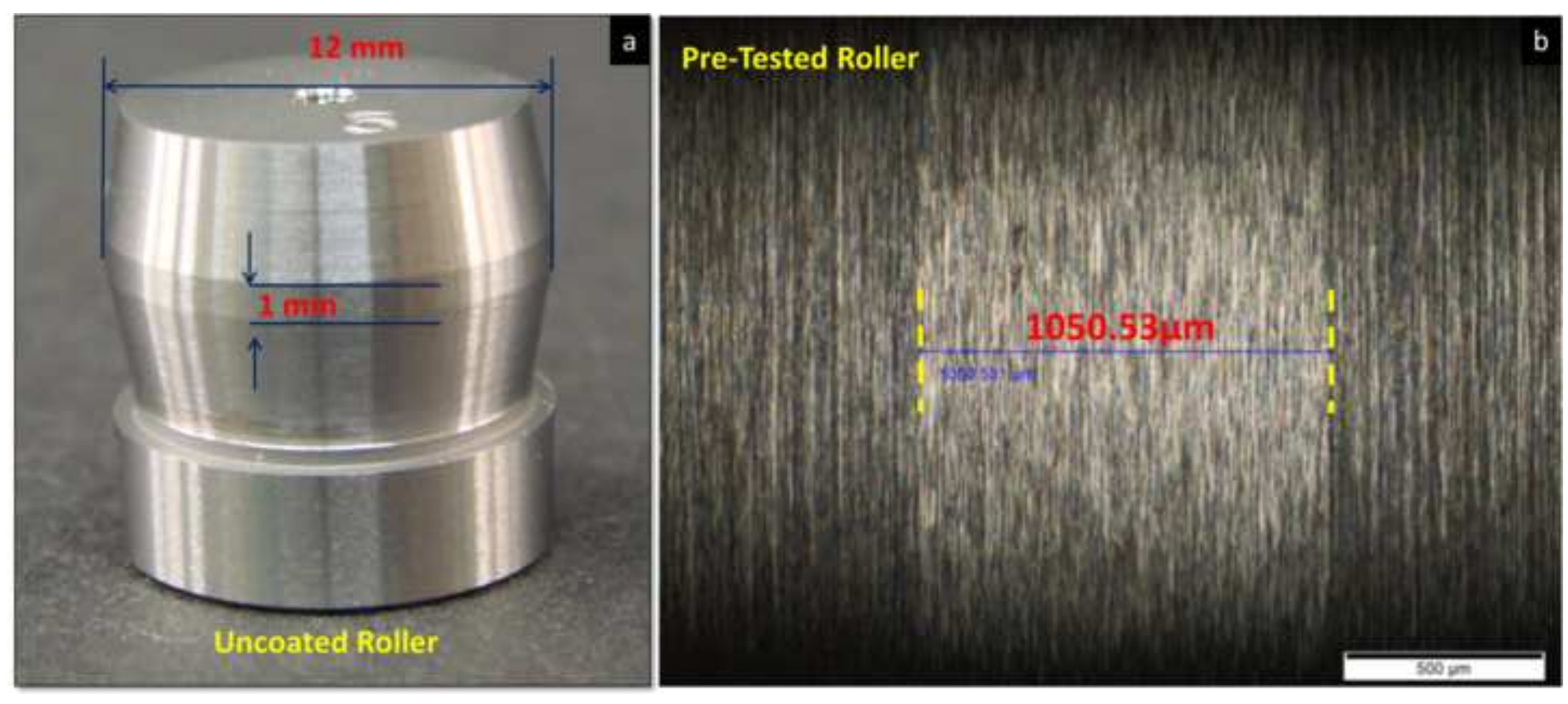


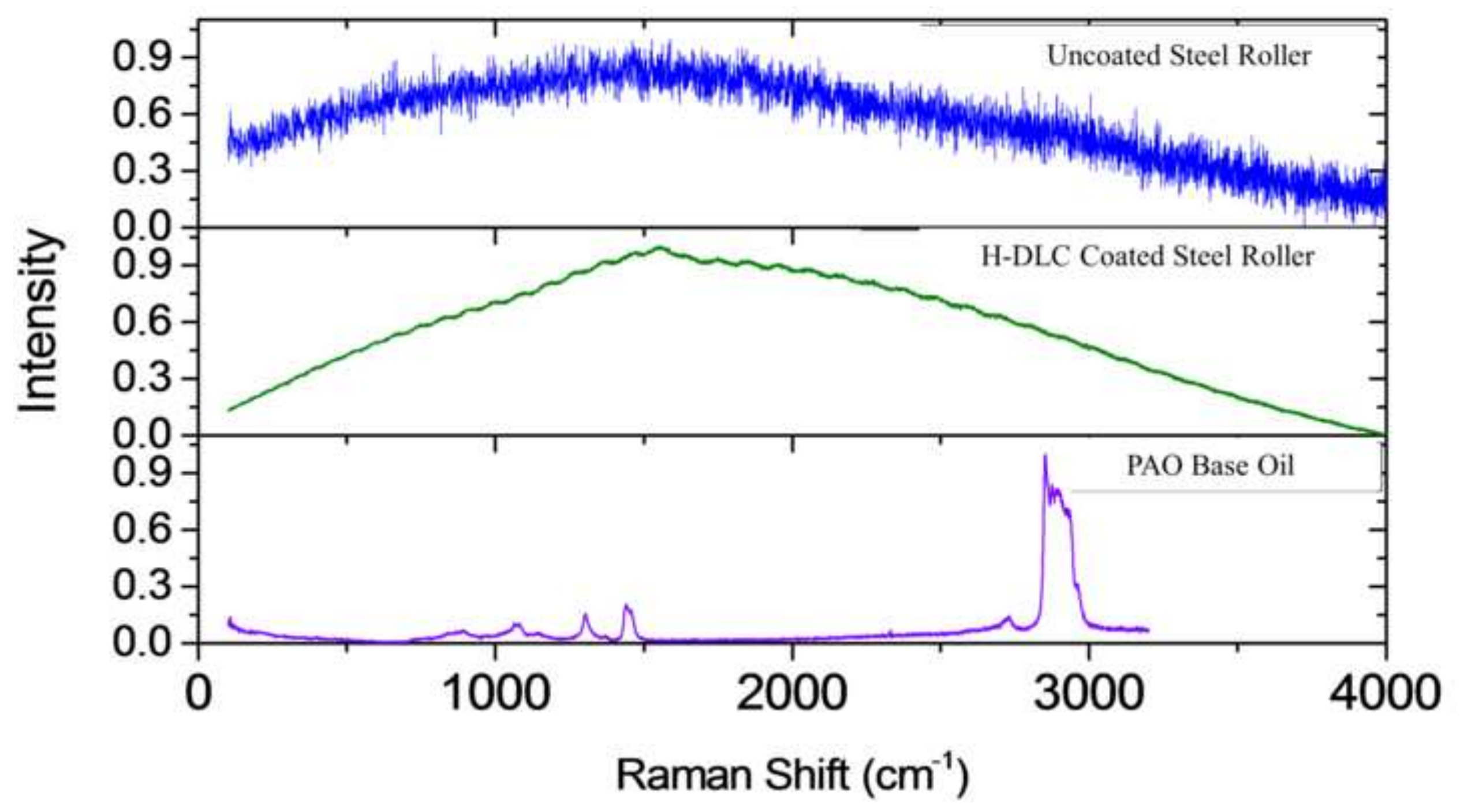


- $\mathrm{Er}=\mathrm{H}$

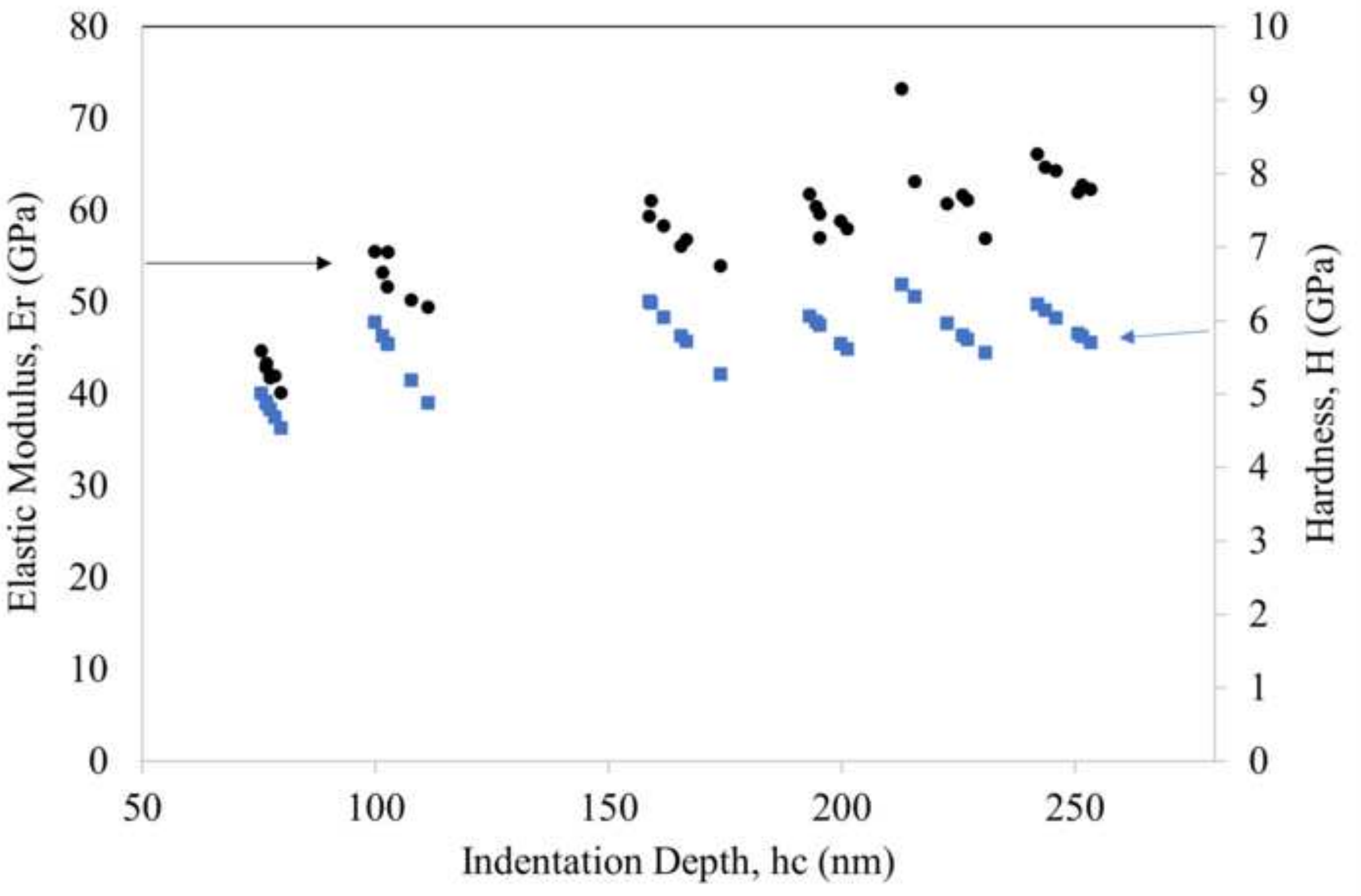




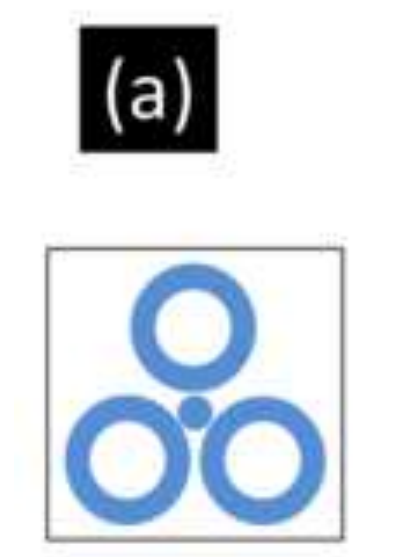

Uncoated Roller on Uncoated Rings
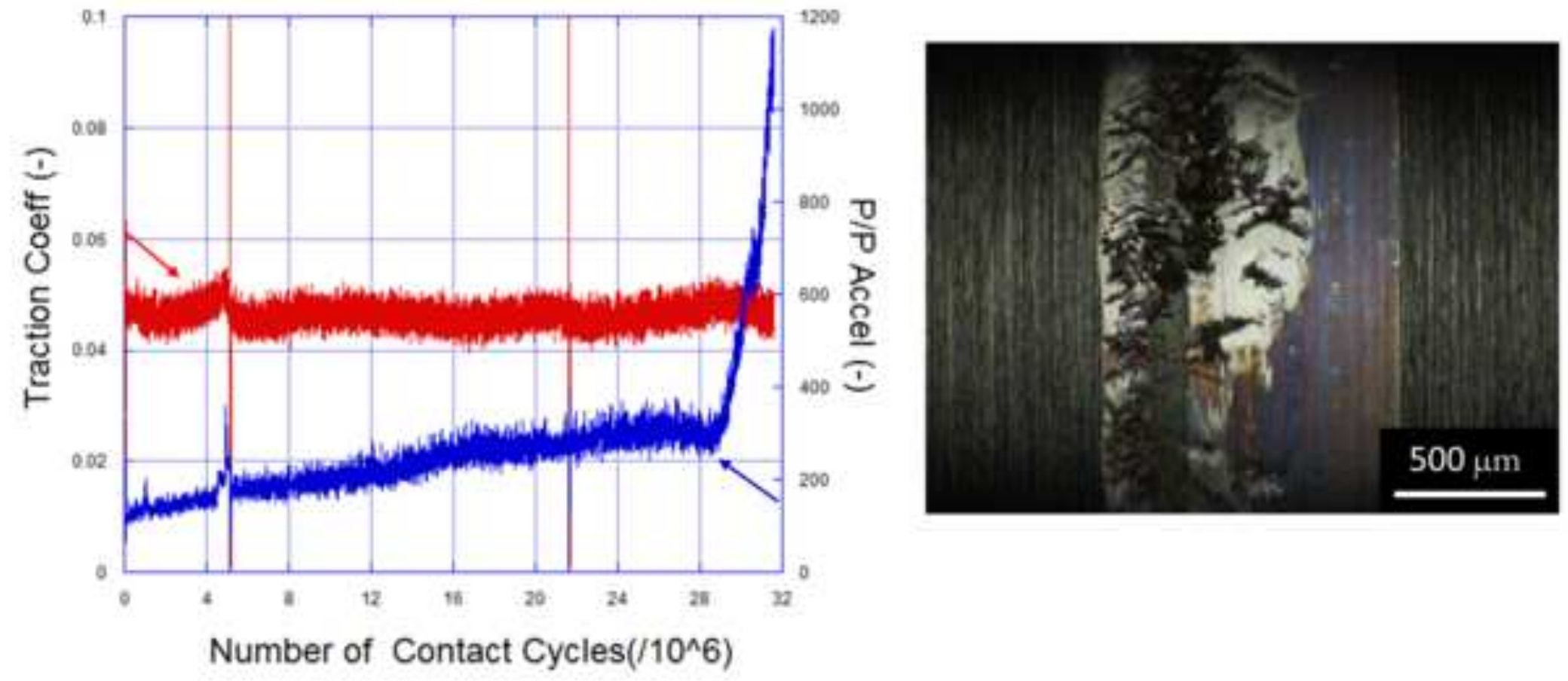


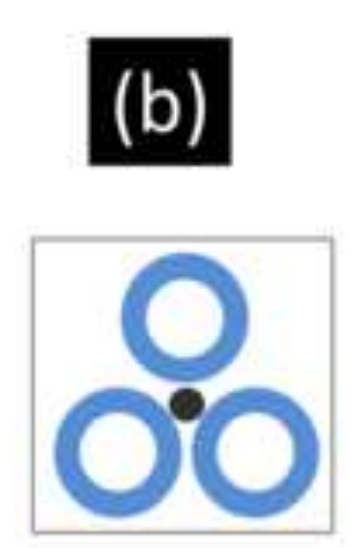

Coated Roller on Uncoated Rings
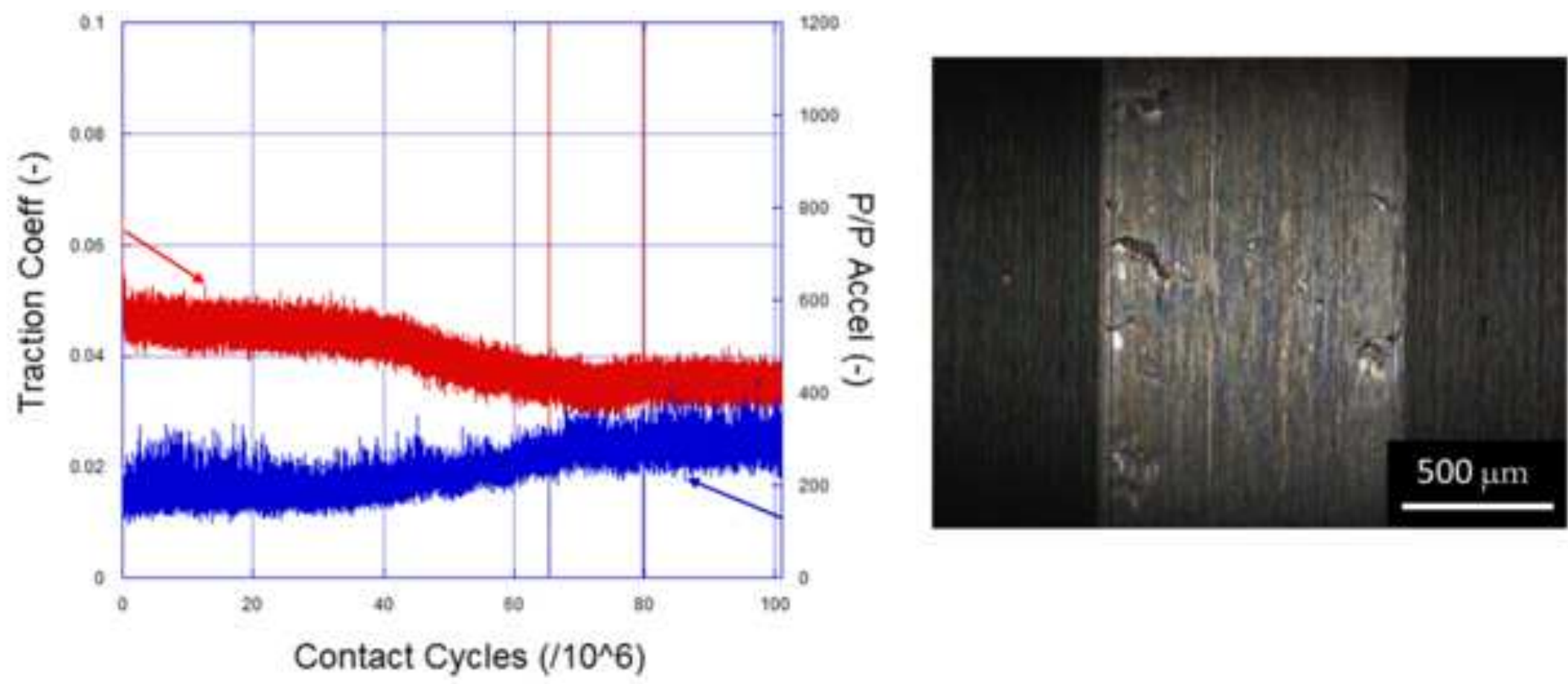
Uncoated Roller on Coated Rings
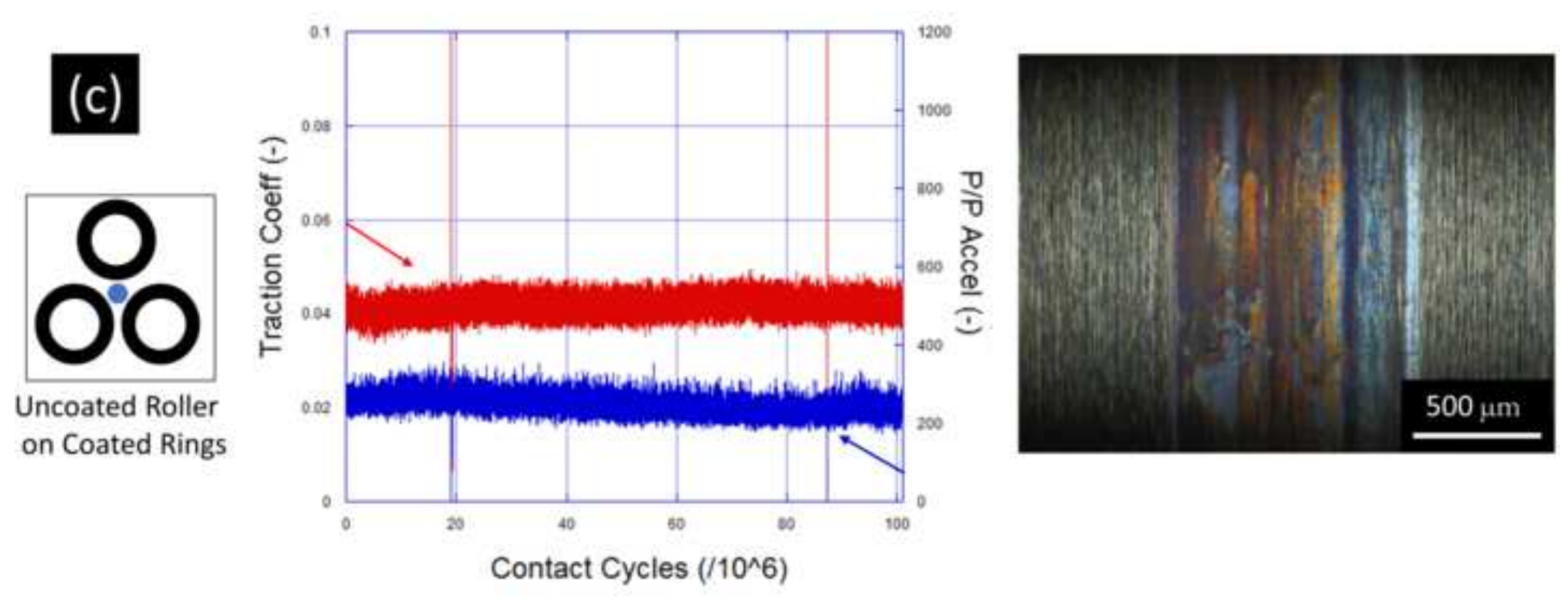


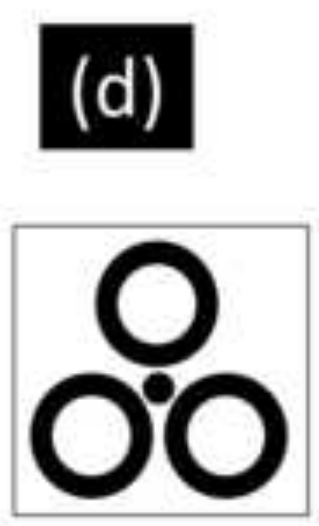

Coated Roller on Coated Rings
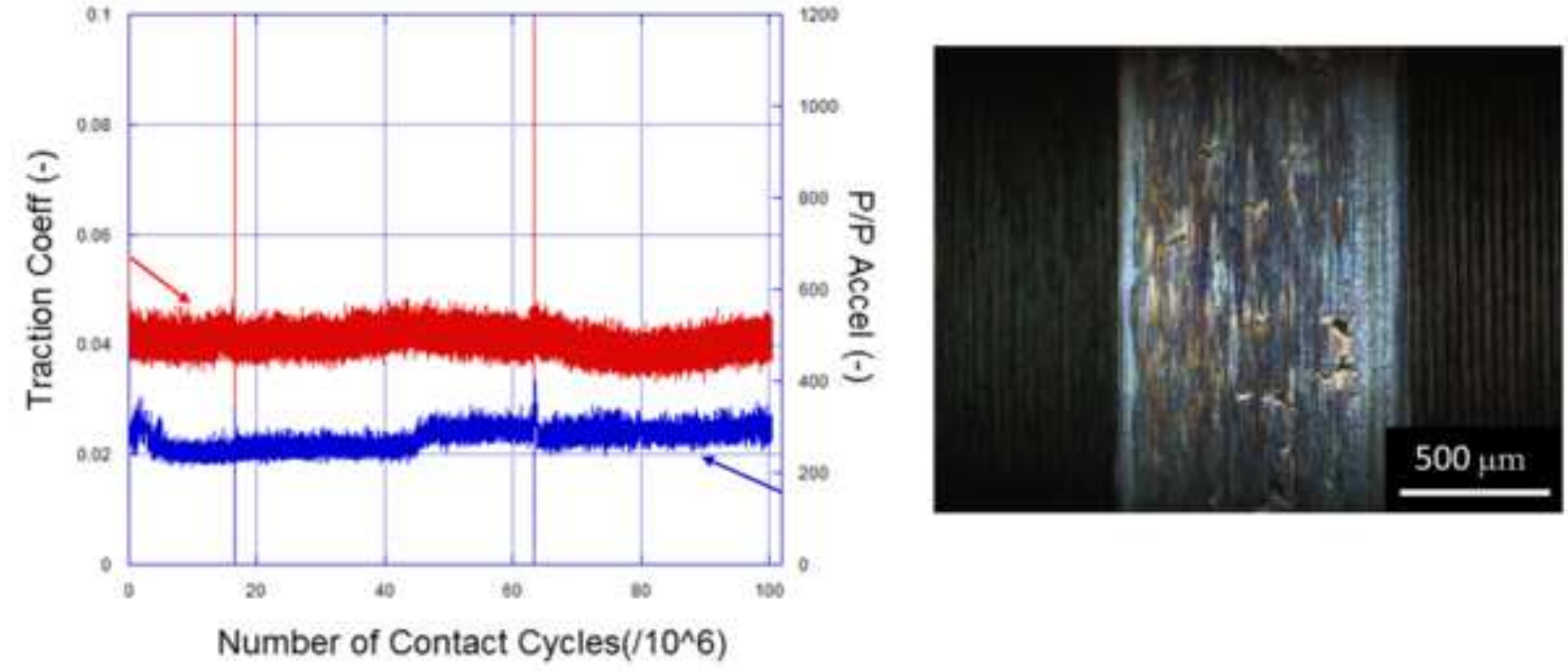

Number of Contact Cycles $\left(/ 10^{\wedge} 6\right.$ ) 

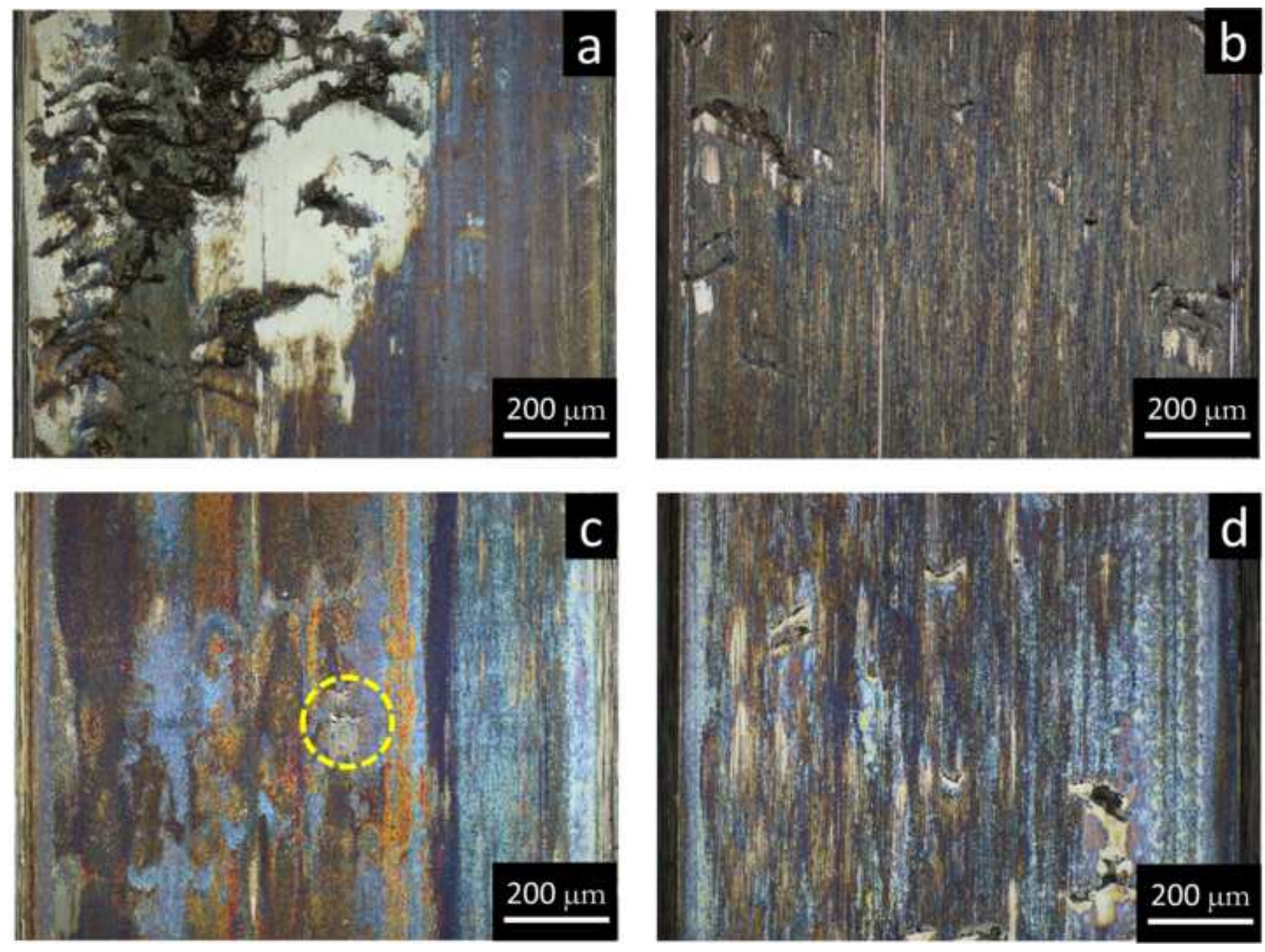

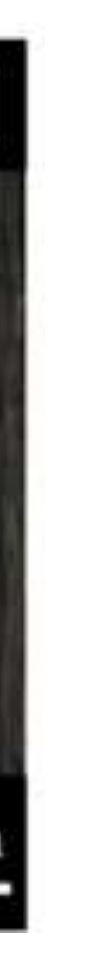

\section{Figure}

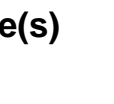

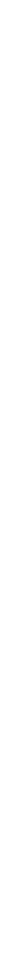

. 


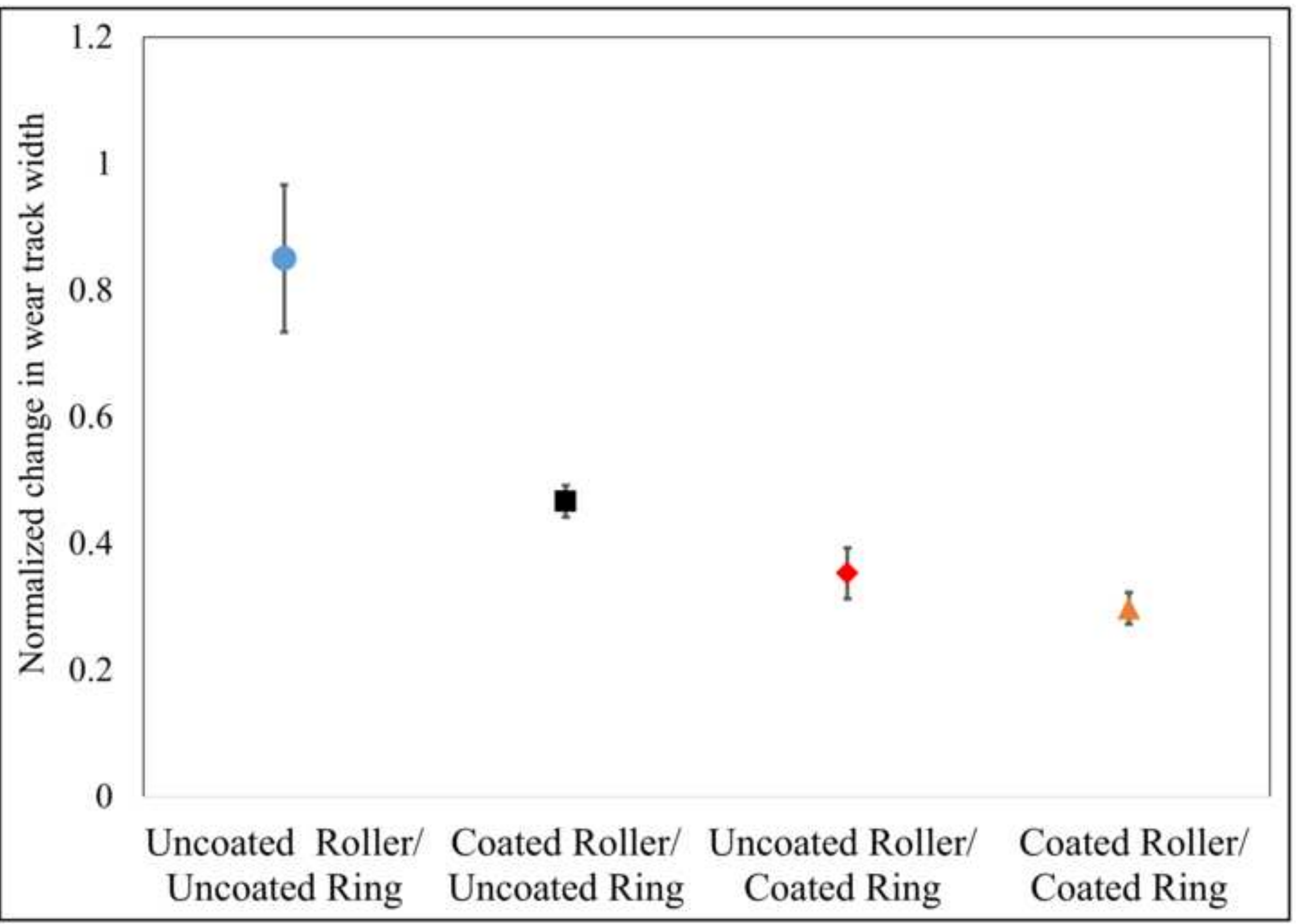




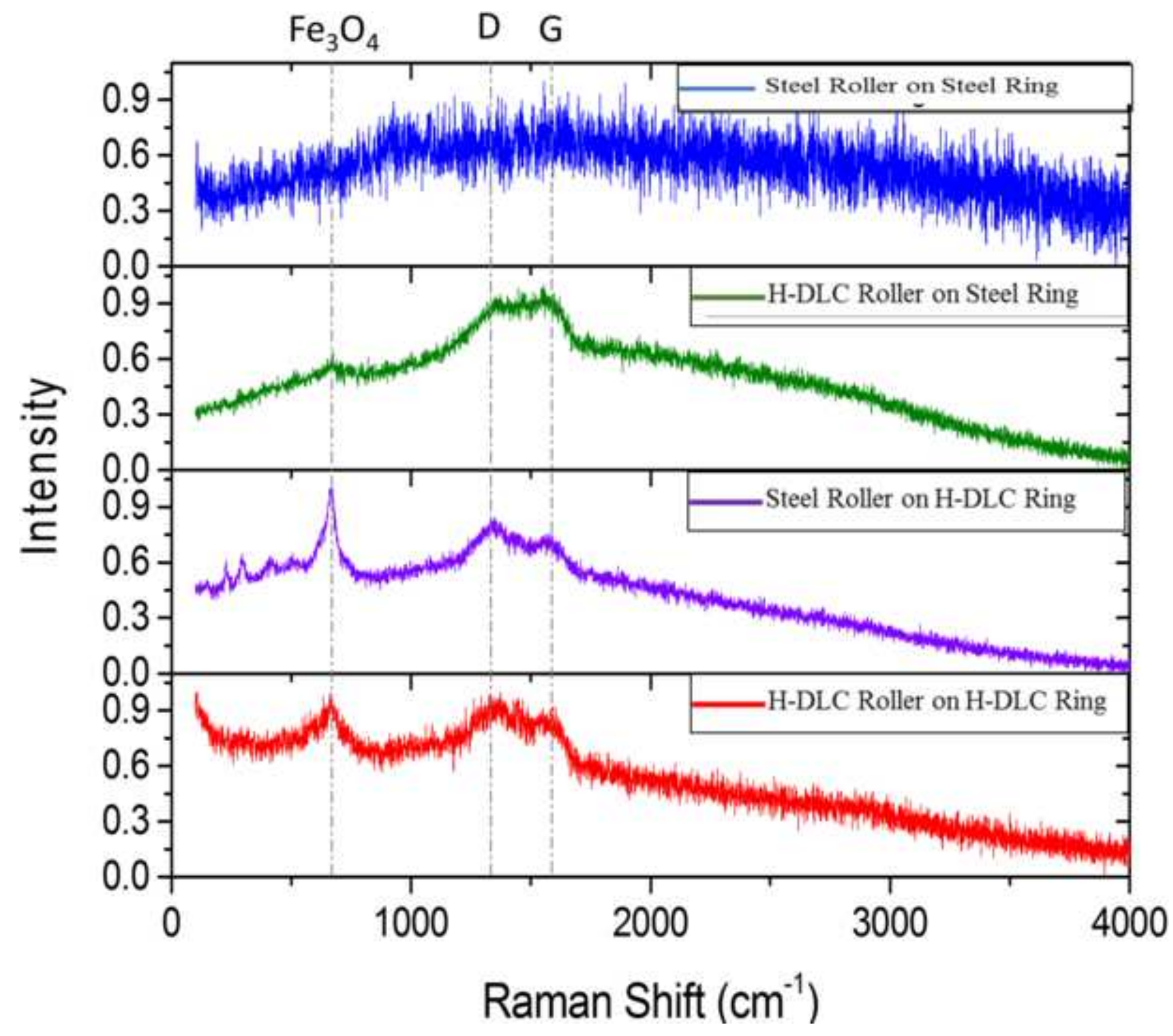


Table 1. Test Material and Properties

\begin{tabular}{|c|c|c|c|c|}
\hline Specimen Type & Material & $\begin{array}{c}\text { Hardness } \\
\text { (HRC) }\end{array}$ & Roughness, $\mu \mathrm{m}$ & Diameter, mm \\
\hline
\end{tabular}

\begin{tabular}{ccccc}
\hline Rings & AISI 52100 Steel & $63-65$ & 0.2 & 54.15 \\
Roller & AISI 52100 Steel & $57-60$ & 0.3 & 12 \\
\hline
\end{tabular}


Table 2. Test Parameters

\begin{tabular}{ccccccc}
\hline $\begin{array}{c}\text { Lubricant } \\
\text { Type }\end{array}$ & Force, N & $\begin{array}{c}\text { Hertzian } \\
\text { Stress, } \\
\text { GPa }\end{array}$ & $\begin{array}{c}\text { Lambda, } \\
\boldsymbol{\lambda}\end{array}$ & $\begin{array}{c}\text { Speed, } \\
\mathbf{m} / \mathbf{s}\end{array}$ & $\begin{array}{c}\text { Slide to } \\
\text { Roll Ratio } \\
\text { ( SRR) }\end{array}$ & $\begin{array}{c}\text { Temperature, } \\
{ }^{\circ} \mathbf{C}\end{array}$ \\
\hline PAO4 & $430 \mathrm{~N}$ & 1.79 & 0.36 & 3 & $40 \%$ & 55 \\
\hline
\end{tabular}

